\title{
Preservation of ovarian follicles reveals evolution of avian reproductive behaviour
}

Xiaoting Zheng, ${ }^{1,2}$ Jingmai O'Connor, ${ }^{3}$ Fritz Huchzermeyer, ${ }^{4}$ Xiaoli Wang, ${ }^{1}$ Yan Wang, ${ }^{1}$ Min Wang $^{3}$, Zhonghe Zhou ${ }^{3}$

${ }^{1}$ Institute of Geology and Palaeontology, Linyi University, Linyi, Shandong 276000, China;

${ }^{2}$ Tianyu Natural History Museum of Shandong, Pingyi, Shandong 273300, China;

${ }^{3}$ Key Laboratory of Vertebrate Evolution and Human Origin of the Chinese Academy of Sciences,, Institute of Vertebrate Palaeontology and Paleoanthropology, Chinese Academy of Sciences, Beijing 100044, China.

${ }^{4}$ Department of Paraclinical Sciences, Faculty of Veterinary Science, University of Pretoria, Private Bag X 04, Onderstepoort, 0110, South Africa.

The two groups of archosaurs, crocodilians and birds, form an extant phylogenetic bracket for understanding the reproductive behaviour of dinosaurs. This behaviour is inferred from preserved nests, eggs, and even gravid individuals ${ }^{1}$. Data indicates many 'avian' traits were already present in Paraves - the clade that includes birds and their close relatives - and the early evolution of the modern avian form of reproduction was already well on its way ${ }^{2,3}$. Like living neornithine birds, non-avian maniraptorans had daily ovideposition and asymmetrical eggs with complex shell microstructure, and were known to protect their clutches ${ }^{4-6}$. However, like crocodilians, non-avian maniraptorans had two active oviducts (one present in living birds), relatively smaller eggs and may not have turned their eggs the way living birds do ${ }^{1,6}$. Here we report on the first discovery of fossilized mature or nearly mature ovarian follicles, revealing a previously undocumented stage in dinosaur reproduction: reproductively active females near ovulation. Preserved in a specimen of the long boney-tailed Jeholornis and two enantiornithine birds from the Early Cretaceous lacustrine Jehol Biota in northeastern China, these discoveries suggest basal birds only had one functional ovary, but retained primitive morphologies as a result of their lower metabolic rate relative to living birds. They also indicate basal birds reached sexual maturity before skeletal maturity as in crocodiles and paravian dinosaurs. Differences in follicular morphology between Jeholornis and the enantiornithines are interpreted as forming an evolutionary gradient from the reproductive condition in paravian dinosaurs towards neornithine birds. Furthermore, differences between the two enantiornithines indicate this lineage might also have evolved advanced reproductive traits in parallel to the neornithine lineage.

Three specimens of Mesozoic birds from the Tianyu Natural History Museum, Shandong, China (STM), have been identified preserving mature ovarian follicles (a follicle being the primary 
oocyte and the sac in which it is contained ${ }^{7}$ ), in their body cavity. The largest specimen (STM2-51 slab and counter-slab; Figs 1, S1) is referable to Jeholornis sp., a basal bird with a boney tail longer than that of Archaeopteryx (see Supplementary Information). The specimen, in dorsoventral view, preserves approximately 20 follicles ventral to the vertebral column and cranial to the pelvic girdle, overlapped by thoracic ribs. The follicles are all round and subequal in size, ranging approximately 7.1-8.8 $\mathrm{mm}$ in diameter (Figs 1C,D, S2; Table S1); the total number of follicles may have been higher than observed in all specimens, obscured by overlap. In STM2-51, the follicles are distributed in rows between the caudal end of the sternum and the pelvis; the number of follicles in each row decreases caudally (three-four proximally, one-two distally), however this pattern may be exaggerated by a crack that laterally borders the preserved follicles. In the main slab, the follicles are preserved permineralized by a dark macrocrystalline mineral (not eggshell, too thick). In the counterslab, the follicles are preserved as pale, pink impressions although some small crystals of the black mineral are also present (Fig 1C).

The two smaller specimens (STM29-8, STM10-45; Figs 2, S3-7) are referable to Enantiornithes (see Supplementary Information); this large clade forms the sister-group to Ornithuromorpha, the clade that includes living birds, and represents the first major avian radiation ${ }^{8,9}$. The two specimens vary in proportions of the humerus/ulna and femur/tibiotarsus, and the shape of the coracoid indicating they represent different taxa, although poor preservation prevents identifying either specimen at the species level (see Supplementary Information). Both specimens preserve mature ovarian follicles in their body cavity visible in dorsoventral (slab and counterslab) view.

Enantiornithine indet. STM29-8 (Figs 2C, S5) preserves at least 12 follicles in situ along the left side of the vertebral column next to the synsacrum. Two additional follicles are recognized displaced proximally near the left wing. All the follicles are nearly circular, with slight variation in size ranging from $5.8-8.8 \mathrm{~mm}$ in diameter (Table S1). The follicles are preserved as black carbonization in the slab (Figs 2A,C) and as impressions in the counterslab (Fig S4). The surfaces of the follicles preserve an uneven lattice structure of fibres, which may potentially be imprints of the blood vessels from the highly vascularised perifollicular membrane ${ }^{7}$.

Enantiornithine indet. STM10-45 (Fig 2D) preserves fewer follicles (at least five), subequal in size (ranging $6.7-8.8 \mathrm{~mm}$ in diameter; Table S1). The follicles are located on the left of the vertebral column distal to the sternum but cranial to the pelvis; a few disarticulated rib elements 
overlap the follicles. Four well-preserved follicles are associated together (possibly obscuring more follicles); an additional follicle(s) is caudally displaced slightly from the others (estimated total five to seven preserved). The surfaces of the follicles are marked by small, black, circular spots of mineralization; the roundness of these structures may suggest preservation of the follicles in STM10-45 was bacterially mediated.

The circular structures interpreted as follicles are clearly located in the body cavity of these fossil birds; in both the slab and counterslab they are preserved overlapping with bone. The structures are not considered seeds preserved in the stomach based on their morphology and position (E. M. Friis pers. comm), as well as comparison with other types of seeds observed in Jehol fossils. In Jeholornis prima IVPP (Institute of Vertebrate Palaeontology and Paleoanthropology, Beijing, China) V13274, which preserves seeds in its stomach ${ }^{10}$, the seeds are more numerous, larger (about $10 \mathrm{~mm}$ in diameter), differ in shape (tapered at one end, not circular) and the surface is ornamented. The seeds are distributed more ventrally while the follicles in Jeholornis STM2-51 are dorsally located along the vertebral column and just cranial to the pelvis, consistent with the position of the ovaries in living archosaurs. Seeds are also preserved in the crop of some Jehol birds (Sapeornis, Hongshanornis) ${ }^{11}$; in these specimens, the crop is found cranial to the sternum and the seeds differ from the follicles in that they are uneven in size and morphology (less round). These structures are clearly not gastroliths, which are commonly preserved in a large number of Jehol ornithuromorph birds ${ }^{11}$; these stones are always preserved nearly as in life: 3-dimensional, numerous, varying in shape, size, and mineral composition, with polished surfaces. Furthermore, gastroliths are proportionately much smaller than the soft-tissue structures preserved here. The circular shape of the preserved structures is consistent with two-dimensional preservation of a spherical structure such as the mature follicles of the ovary (single enlarged cells). The absence of any preserved eggshell and their clumped association, with no caudally located in situ follicles, indicates the follicles had not entered the oviducts.

Living archosaurs - crocodilians and birds - differ greatly in their reproductive habits in terms of clutch size, nesting behaviour, degree of parental care, developmental strategy of young, posing the evolutionary questions: when, how, and why did derived avian reproductive traits evolve within Dinosauria? The evidence indicates that while the non-avian theropod reproductive system retained some primitive archosaurian traits (i.e. two functional oviducts, hyper-ellipsoidal 
eggs, precocial off-spring), derived bird-like characteristics were also present (deposited one egg per oviduct per day, larger eggs relative to body size, complex eggshell microstructures, asymmetrical eggs, parental care) ${ }^{1,5,6,12}$. However, information on the soft-tissue anatomy of reproductive organs and the sequence and timing of changes in reproduction strategy within Aves itself, remains poorly understood. These new specimens provide the first glimpse of how basal birds reproduced. They also record a fairly wide bracket within the Mesozoic bird phylogenetic tree (Fig 3), thus revealing different stages of evolution.

In living archosaurs, as in all vertebrates, the female reproductive system is generally divided into two separate parts: the ovary and oviduct ${ }^{13,14}$. Birds are unique among amniotes, in that although the embryo has two ovaries and oviducts, only the left ovary and oviduct are functional in the adult. The kiwi differs from other birds in that both the left and right ovaries develop (and are functional), though it is only the left oviduct that develops (other exceptions occur particularly among birds of prey) ${ }^{14}$. The ovary contains all the female reproductive oocytes - the number diminishes during the life span of the individual although the ovary itself enlarges as the bird approaches reproductive maturity. Each reproductive cycle, some of the normally small oocytes mature into follicles, becoming enlarged through yolk deposition (vitellogenesis) in preparation for ovulation. In crocodiles, similar to birds, the follicles do not mature all at once, forming a hierarchy that reflects the order in which follicles will ovulate. Crocodilians have a low metabolic rate so vitellogenesis lasts an extended period of time (months compared to four to 16 days in birds $)^{14,15}$; as a result, the follicular hierarchy is much less distinct in crocodilians and mature follicles are subequal in size ${ }^{15}$. Living birds have a high metabolic rate and yolk deposition is rapid resulting in strongly apparent follicular hierarchy ${ }^{7}$ (Fig 3). No medullary bone (a rapidly mobilized source of eggshell calcium in living birds) forms prior to ovideposition ${ }^{16,17}$ - instead, crocodilians access calcium from structural bone ${ }^{18}$. Female crocodilians will ovulate a full clutch of up to 60 eggs (average clutch size ranges from 12 to 48 among living crocodilians) ${ }^{19}$, and store the eggs in the distal end of the oviduct for several weeks - egg laying occurs en masse when the embryos are approximately at the 18 somite stage ${ }^{18}$. Although the adult guards the nest and young, eggs are passively incubated and young are not typically fed by the adult - a highly precocial developmental strategy. Living birds (Neornithes) ovideposit daily with the exception of the paleognaths, which lay one egg every two - six days ${ }^{14}$. 
Non-avian maniraptoran dinosaurs are known to have two active oviducts, from the paired association of eggs in the body cavity of one specimen ${ }^{5}$. Why modern birds lost the right ovary and oviduct is unclear; the most common hypothesis suggests this was related to the need to reduce weight in flight during the reproductive season, the female having to carry only a single egg inside rather than two, although loss may also have been to alleviate the demands for calcium during ovulation ${ }^{20}$. As the follicles are interpreted as being in the ovaries of these specimens we cannot comment directly on the number of functioning oviducts; however, both enantiornithines, in dorsal view, preserve the association of follicles clearly on the left side of the body. The position of the ovary is not clear in Jeholornis STM2-51; however, the thoracic vertebrae dorsal to the follicles are preserved in left lateral view and the follicles appear to be isolated to the left side, as in the enantiornithines, suggesting only the left ovary was active. Since the closest related dinosaurs are known to have two functioning oviducts, the loss of function in the right ovary is inferred to have occurred very close to the non-avian maniraptoran-avian transition, supporting the hypothesis that its loss is flight related. Notably, it is documented in some crocodilians that the right ovary is the larger of the two, producing a greater number of mature follicles (and thus having a greater weight) ${ }^{15}$.

The large and even size of the follicles preserved in these specimens suggests these female individuals were ready or near ready to ovulate; if the birds were in the early stages of vitellogenesis, follicle size would not be so large and consistent. The slightly higher variation in size among the follicles preserved in STM29-8 may suggest that vitellogenesis was incomplete. Alternatively, this may imply that vitellogenesis occurred more rapidly and over a shorter period of time, producing a more distinct follicular hierarchy, similar to living birds. This latter hypothesis is consistent with the smaller number of follicles relative to Jeholornis and the more derived phylogenetic placement of enantiornithines. The ovaries are not preserved in their entirety. We infer that the immature oocytes, previtelline follicles, and atretic follicles in the ovary were either not preserved or are not visible (small, obscured by overlap) - potentially a combination of both. We hypothesize that the presence of a perivitelline layer and other protective layers (absent in immature oocytes) ${ }^{7}$ facilitated preservation of the mature follicles (see Supplementary Information). The absence of eggs in the oviduct(s) suggests ovulation had not yet begun; alternatively, the animal may have died in the time between laying one egg and ovulating another (typically less than an hour in living birds), or egg(s) in the oviduct(s) may 
have been expelled from the body after death, similar to the female pterosaur reported from the Jurassic of China ${ }^{21}$.

In the long-tailed bird Jeholornis STM2-51 the size of the follicles is very consistent (Fig 1C,D), suggesting a more crocodilian style of reproduction, in which a large number of follicles reach maturity near simultaneously so that follicular hierarchy is minimal ${ }^{22}$. This suggests that vitellogenesis occurred more slowly, similar to crocodilians, and is consistent with the lower metabolic rate relative to extant taxa predicted for basal birds ${ }^{23}$. The preserved size of the follicles suggests egg-size was large relative to the body in basal birds, despite morphological restrictions such as distally contacting pubes; eggs would have been too large to store in the body and so ovideposition would have to occur between ovulation, as in other maniraptorans and living birds but unlike crocodiles 5 .

In a healthy and undisturbed female, all mature follicles will ovulate and thus the number of mature follicles is a good proxy for clutch size $\mathrm{e}^{7,15}$. Crocodilians have much larger clutches than birds but the follicle (and complete egg) is much smaller compared to the adult body size. In Alligator mississippiensis the mature follicle has a width of $45 \mathrm{~mm}$; the follicle to femur ratio changes with age but averages $0.017^{15,24}$. Comparative data on follicle size is limited but in Gallus mature follicles reach $40 \mathrm{~mm}^{7}$ (size exaggerated through domestication), comparable to that of A. mississippiensis despite their vast difference in body size (follicle diameter to femur length ratio 0.51). Although the absolute size of the preserved follicles, inferred to be slightly exaggerated by compression, is similar between the three specimens, the adult body size differs considerably: Jeholornis STM2-51 body mass is estimated at $676 \mathrm{~g}$; enantiornithine STM29-8 is estimated to be $125 \mathrm{~g}$; enantiornithine STM10-45 is estimated to be $105 \mathrm{~g}$ (we use Liu et al. ${ }^{25}$ to estimate body mass; Table S2). As a result, each specimen has a distinct egg to body size ratio. Jeholornis sp. STM2-51 preserves the largest number of follicles, which are proportionately the smallest compared to overall body size (follicle diameter to femur length ratio of 0.087 ), consistent with the basal position of this taxon within Aves (only more derived than Archaeopteryx). The larger enantiornithine STM29-8 preserves a larger number of smaller follicles (follicle:femur ratio 0.171), while the smaller enantiornithine STM10-45 preserves only a few follicles nearly the same size as Jeholornis STM2-51, despite the disparity in their overall body size (follicle:femur ratio 0.217). These specimens show the same trade-off between egg 
size and clutch size observed in living birds ${ }^{26}$. The large clutch size in Jeholornis STM2-51 and Enantiornithes indet. STM29-8 is consistent with the precocial reproductive strategy inferred for basal birds ${ }^{27}$. The smaller clutch preserved in Enantiornithes indet. STM10-45 (although potentially an artefact of preservation) suggests that enantiornithines may also have been diverse in their reproductive strategies.

Another major difference between living archosaurs is the timing of sexual maturation. In crocodilians reproductive maturity has an early onset, before the animal reaches skeletal maturity. Modern birds grow rapidly, typically reaching skeletal maturity within a year although not typically becoming sexually mature until later (two to eight years; only six months in the domestic chicken $)^{7,14}$. Histological analyses of paravian dinosaurs reveal a crocodilian pattern of reaching sexual maturity before skeletal maturity ${ }^{28}$. Enantiornithine STM10-45 shows a clear absence of fusion in compound bones like the carpometacarpus (SFig. 8). In Enantiornithes, compound bones are known to fuse late in ontogeny ${ }^{8}$, and STM10-45 is regarded as a subadult indicating that, in at least this lineage of enantiornithines, reproductive maturity was achieved prior to skeletal maturity, as in paravian dinosaurs and crocodilians. Histological analysis was attempted on the three specimens; unfortunately, no bone could be sampled from STM10-45. Samples from STM2-51 and STM29-8 were badly crushed and the medullary cavity was not clearly preserved preventing identification of medullary bone (see Supplementary Information). However, it was determined that enantiornithine STM29-8, which shows a greater degree of fusion in the compound bones (poor preservation prevents determining the exact degree of fusion), was skeletally mature and required more than one year to reach adult size (see Supplementary Information).

The preservation of reproductive organs such as ovarian follicles allows a rare opportunity to confidently identify the gender of these specimens and recognize sexually dimorphic traits. The elongate paired tail feathers present in some enantiornithines strongly resemble those of Confuciusornis, which have been interpreted as a sexually dimorphic trait present only in males; this interpretation is controversial as the feathers do not co-vary with size as expected ${ }^{29}$. Feathers are only preserved in STM29-8 (Fig 2A). The feathers around the pygostyle are clearly preserved and confirm the absence of paired elongate rectrices in this reproductively mature (adult) female. 
The ovarian follicles preserved in these Early Cretaceous birds, the first discovery of this kind, reveal new clues regarding basal bird reproduction. Based on the bracket placed by the fossil record, the consistent preservation of the follicles on the left side of the body in all three specimens suggests that the right functional ovary was lost at the dinosaur-avian transition. Clutch size in basal birds is inferred to be plesiomorphically large, consistent with the precocial developmental strategy inferred from embryos and juveniles, and information from closely related dinosaurs. Within Aves there is an observable trend towards smaller clutches with relatively larger eggs that extends from long boney-tail birds closely related to Archaeopteryx into Neornithes, and clade specific specializations in reproduction strategy were not limited to the crown group. Despite the presence of advanced features, the ovary in Mesozoic birds was large with minimal follicular hierarchy and sexual maturity preceded skeletal maturation like in crocodilians, both conditions consistent with the lower metabolic rate inferred for basal birds and paravian dinosaurs compared to neornithine birds.

\section{Methods Summary}

Specimens were studied using a Motic K-500L microscope. Two histological samples each were taken from STM2-51 and STM29-8 and studied under normal and polarized light using a Leica DM-RX polarizing microscope.

\section{Methods}

Bone samples were taken from all three specimens; only a single sample could be retrieved from STM10-45 and it could not be used for histological analysis. Two samples were taken from each of the other specimens where the bone was already broken, as close to midshaft as preservation allowed: the ulna and femur were sampled in STM2-51 and the humerus and femur were sampled in STM29-8. The samples were taken using a micro-saw and were embedded in EXAKT Technovit 7200 one-component resin and allowed to dry for 24 hours. The samples were then cut and polished until the desired optical contrast was reached. The samples were viewed under normal and polarized light using a Leica DM-RX polarizing microscope.

\section{References}


${ }^{1}$ Zelenitsky, D., Reproductive traits of non-avian theropods in Proceedings of the 2006 Goseong International Dinosaur Symposium, edited by Y.-N. Lee (2006), Vol. 22, pp. 209-216.

${ }^{2}$ Zhou, Z. \& Zhang, F., A precocial avian embryo from the Lower Cretaceous of China. Science 306, 653 (2004). ${ }^{3}$ Chiappe, L.M., Ji, S., \& Ji, Q., Juvenile birds from the Early

Cretaceous of China: implications for enantiornithine ontogeny. Am Mus Novit 3594, 1-46 (2007). ${ }^{4}$ Norell, M.A., Clark,

J.M., Chiappe, L.M., \& Demberelyin, D., A nesting dinosaur. Nature 378,

774-776 (1995). ${ }^{5}$ Sato, T., Chang, Y.-N., Wu, X.-C., Zelenitsky, D.A., \& Hsiao, Y.-F., A

pair of shelled eggs

inside a female dinosaur. Science 308, 375 (2005). ${ }^{6}$ Varricchio, D.J., Jackson, F.,

Borkowski, J.J., \& Horner, J.R., Nest and egg clutches of the dinosaur Troodon formosus and the evolution of avian reproductive traits. Nature 385, 247-250 (1997). ${ }^{7}$ Gilbert, A.B., Female genital organs in Form and Function in Birds, edited by A.S. King \& J.

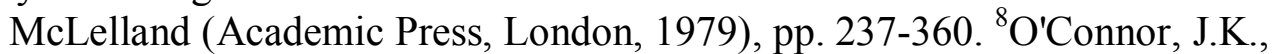
University of Southern California, 2009. ${ }^{9}$ O'Connor, J.K., Chiappe, L.M., \& Bell, A., Pre-modern Birds: Avian Divergences in the Mesozoic in Living Dinosaurs: the Evolutionary History of Birds, edited by G. D. Dyke \& G. Kaiser (J. Wiley \& Sons, New Jersey, 2011), pp. 39-114. ${ }^{10}$ Zhou, Z. \& Zhang, F., A long-tailed, seed-eating bird from the Early Cretaceous of China.

Nature 418, 405-409 (2002). ${ }^{11}$ Zheng, X.-T. et al., Fossil evidence of avian crops from the Early Cretaceous of China. Proc. Natl. Acad. Sci. USA 108 (38), 15904-15907 (2011). ${ }^{12}$ Clark, J.M., Norell, M.A., \& Chiappe, L.M., An oviraptorid skeleton from the Late Cretaceous of Ukhaa Tolgod, Mongolia, preserved in an avianlike brooding position over an oviraptorid nest. Am Mus Novit 3265, 1-36 (1999). ${ }^{13}$ Girling, J.E., The reptilian oviduct: a review of structure and function and directions for future research. J Exp Zool 293, 141-170 (2002). ${ }^{14}$ Gill, F.B., Ornithology, 3rd Edition. (W.H. Freeman and Company, New York, 2007). ${ }^{15}$ Lance, V.A., Reproductive cycle of the American Alligator. Am Zool 29 (3), 999-1018 (1989). ${ }^{16}$ Schweitzer, M.H., Wittmeyer, J.L., \& Horner, J.R., Gender-specific reproductive tissue in ratites and Tyrannosaurus rex. Science 308, 1456-1460 (2005). ${ }^{17}$ Schweitzer, M.H., Elsey, R.M., Dacke, C.G., Horner, J.R., \& Lamm, E.-T., Do egg-laying crocodilian (Alligator mississippiensis) archosaurs form medullary bone? Bone 40 (4), 1152-1158 (2007). ${ }^{18}$ Richardson, K.C., Webb, G.J.W., \& Manolis, S.C., Crocodiles:

Inside Out. (Surrey Beatty \&

Sons, Chipping Norton, 2003). ${ }^{19}$ Thorbjarnarson, J.B., Reproductive characteristics of the order Crocodylia. Herpetologica $\mathbf{5 2}$

(1), 8-24 (1996). ${ }^{20}$ Taylor, T.G., How an eggshell is made. Sci Am 222, 88-95 (1970).

${ }^{21}$ Lü, J.-C. et al., An egg-adult association, gender, and reproduction in pterosaurs. Science 331, 321-324 (2011). ${ }^{22}$ Astheimer, L.B., Manolis, S.C., \& Grau, C.R., Egg formation in crocodiles: avian affinities in yolk deposition. Copeia 1, 221-224 (1989). ${ }^{23}$ Erickson, G.M. et al., Was dinosaurian physiology inherited by birds? Reconciling slow growth in Archaeopteryx. PLoS ONE 4 (10), e7390 (2009). 
${ }^{24}$ Farlow, J.O., Hurlburt, G.R., Elsey, R.M., Britton, A.R.C., \& Langston, W., Jr., Femoral dimensions and body size of Alligator mississippiensis: estimating the size of extinct mesoeucrocodylians. J Vertebr Paleontol 25 (2), 354-369 (2005).

${ }^{25}$ Liu, D., Zhou, Z.-H., \& Zhang, Y.-G., Mass estimate and evolutionary trend in Chinese Mesozoic fossil birds. Vertebr Palasiat 50 (1), 39-52 (2012).

${ }^{26}$ Godfray, H.C.J., Partridge, L., \& Harvey, P.H., Clutch size. Annual Review of Ecology 22, 409-429 (1991).

${ }^{27}$ Varricchio, D.J. et al., Avian paternal care had dinosaur origin. Science 322, 1826-1828 (2008).

${ }^{28}$ Erickson, G.M., Rogers, K.C., Varricchio, D.J., Norell, M.A., \& Xu, X., Growth patterns in brooding dinosaurs reveals the timing of sexual maturity in non-avian dinosaurs and genesis of the avian condition. Biol Lett (2007).

${ }^{29}$ Chiappe, L.M., Marugán-Lobón, J., Ji, S., \& Zhou, Z., Life history of a basal bird: morphometrics of the Early Cretaceous Confuciusornis. Biol Lett 4 (6), 719-723 (2008).

Supplementary Information is linked to the online version of the paper at www.nature.com/nature.

\section{Acknowledgements}

The specimens reported here are deposited in the Tianyu Natural History Museum, Shandong, China. We thank Shi Aijuan for helping with illustrations and Eamon O'Connor for estimating body mass. The research was supported by the National Basic Research Program of China (973 Program, 2012CB821906), the National Natural Science Foundation of China (41172020) and the Chinese Academy of Sciences.

\section{Author Contributions}

X.Z., J.O'C. and Z.Z. designed the project. J.O’C., F.H., Z.Z., X.W., M.W., and Y.W. performed the research. J.O'C., F.H. and Z.Z. wrote the manuscript.

\section{Author Information}

Reprints and permissions information is available at www.nature.com/reprints.

The authors state there are no competing financial interests.

Correspondence and requests for materials should be addressed to J. O'Connor and Z. Z.

\section{Figure Captions}

Figure 1. Jeholornis sp. STM2-51 preserving mature ovarian follicles: A, photograph of the main slab in dorsal view, scale bar two centimetres; B, interpretative drawing of the slab; C, close up of the follicles indicated by the red square in the main slab photograph; $\mathrm{D}$, close up of the follicles in the counter-slab, scale bar equals one centimetre.

Figure 2. Enantiornithine specimens preserving mature ovarian follicles in dorsal view: A, photograph of the main slab of STM29-8; B, photograph of the main slab of STM10-45; C, close 
up of the follicles in STM29-8 preserved in the region indicated by the red box in part A; D, close up of the follicles in STM10-45 preserved in the region indicated by the red box in part B.

Figure 3. Reconstructions of living archosaurs Crocodylia and Neornithes as well as the three fossilized specimens showing relative ovary morphology mapped over a simplified cladogram of Archosaur relationships. Green lines indicate extant lineages; red lines indicate extinct lineages; dashed lines indicate lineages with no data. 
Figure 1

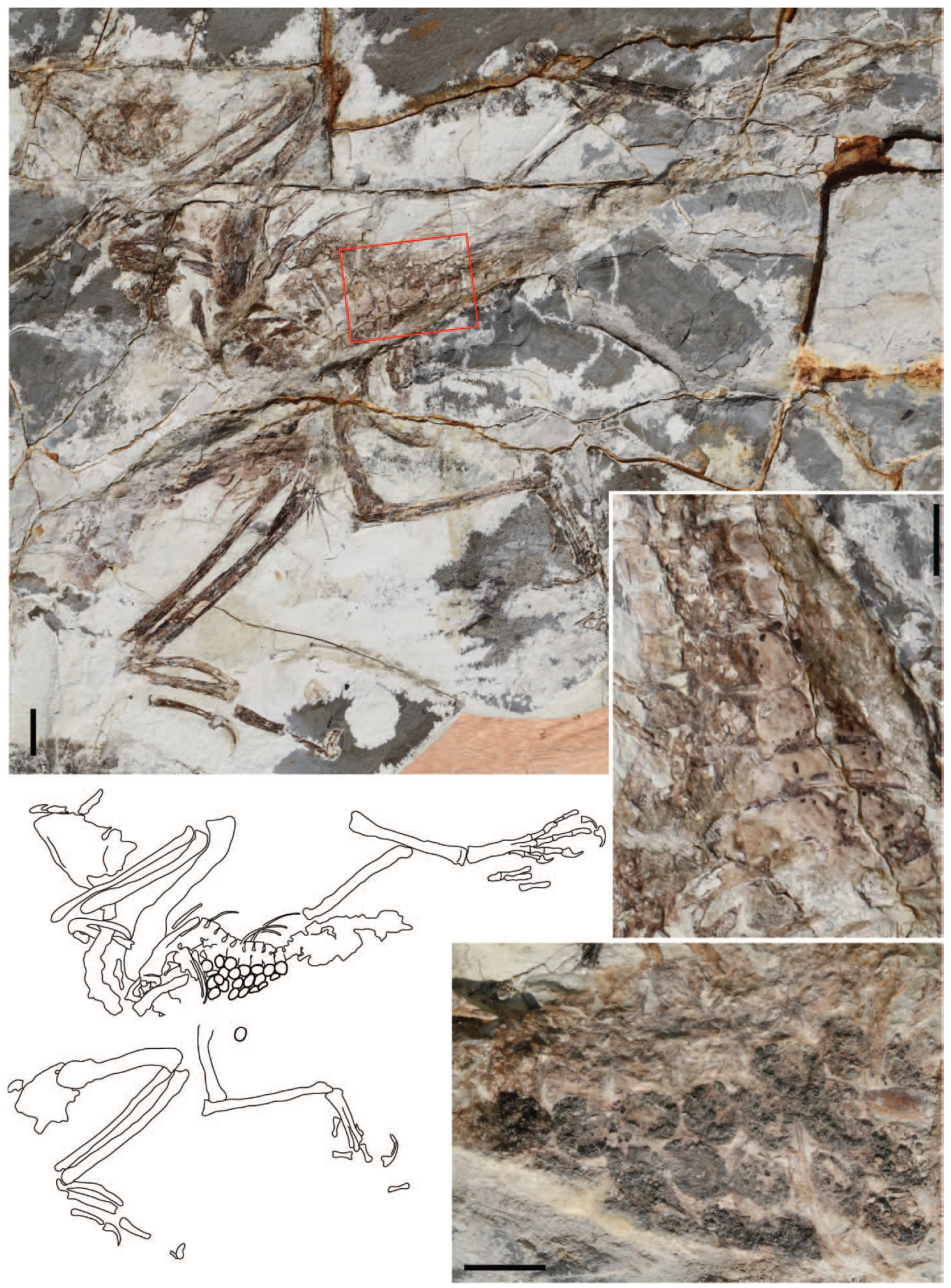


Figure 2

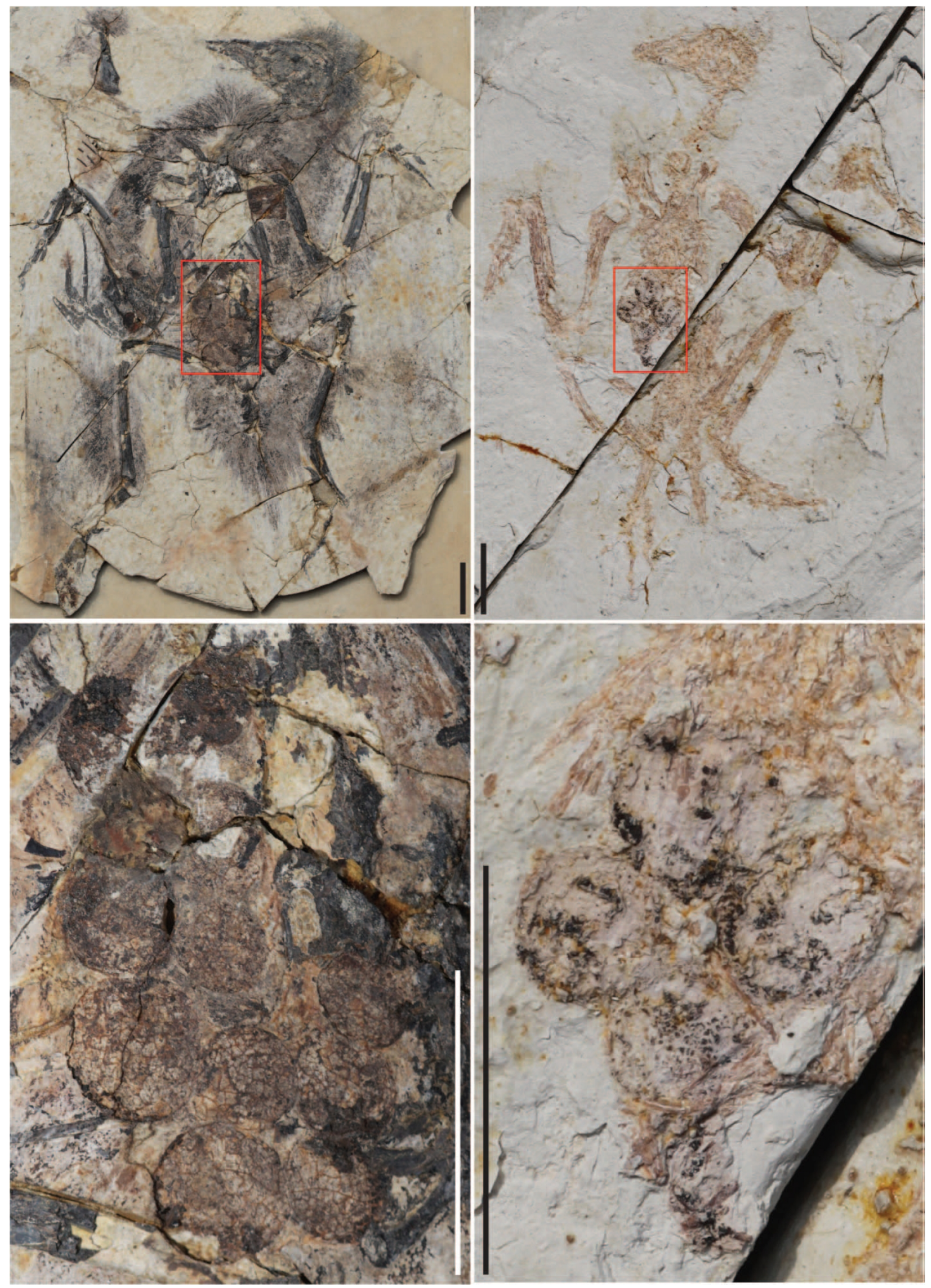


Figure 3

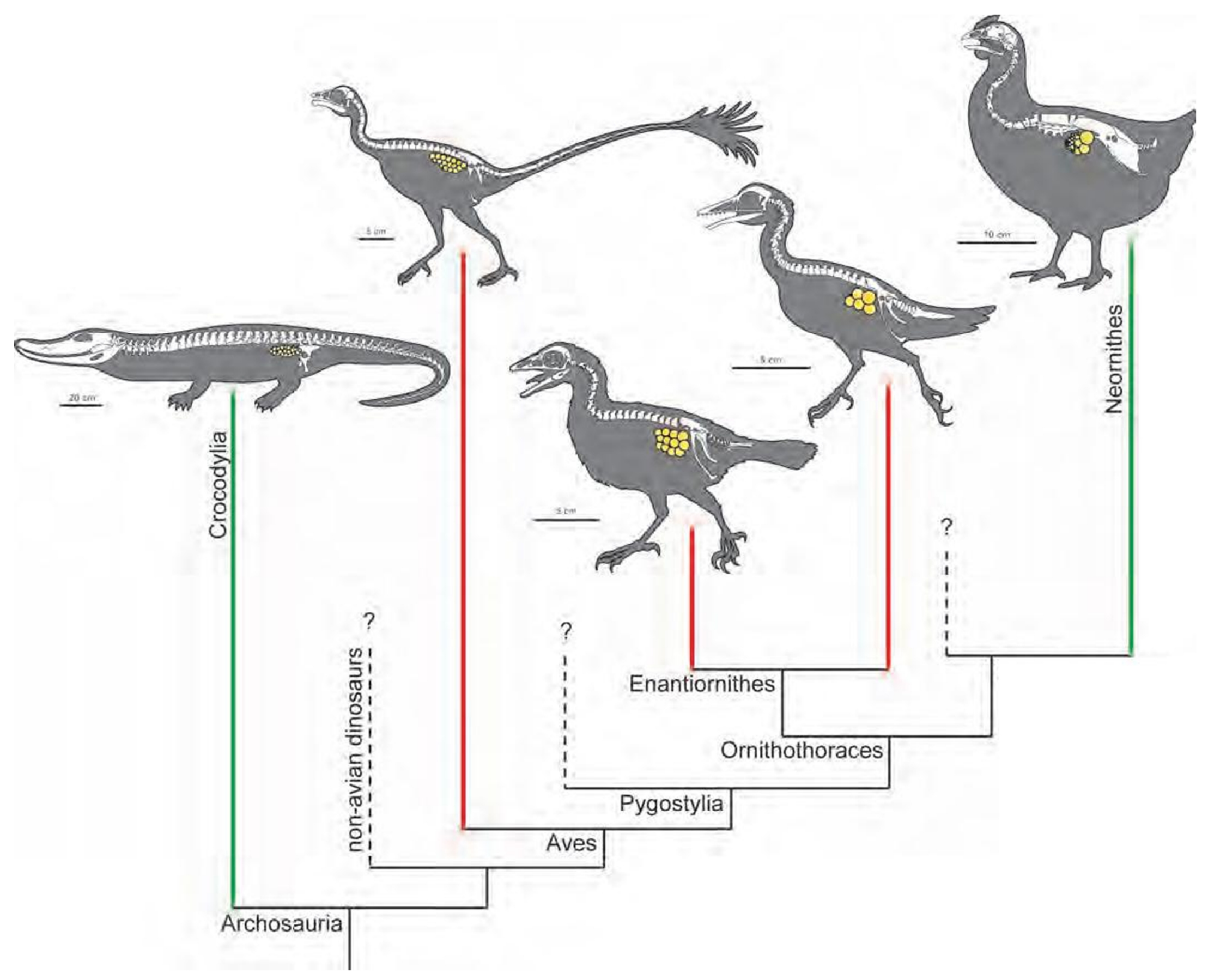

